\title{
Correction to: Allometric approach to crop nutrition and implications for crop diagnosis and phenotyping. A review
}

\author{
Gilles Lemaire ${ }^{1} \cdot$ Thomas Sinclair $^{2} \cdot$ Victor Sadras $^{3} \cdot$ Gilles Bélanger $^{4}$
}

Published online: 11 June 2019

(C) INRA and Springer-Verlag France SAS, part of Springer Nature 2019

\section{Correction to: Agronomy for Sustainable Development https://doi.org/10.1007/s13593-019-0570-6}

Due to a different interpretation of a query about figure numbering during proof stage, figures and captions in above mentioned article got mixed-up in the final version. The publisher and typesetter regret this occurrence and apologize for the inconvenience caused.

In this correction note you will find figures 4 - 8 with correct numbers and captions, as well as the correct version of Box 2 .

The online version of the original article can be found at https://doi.org/ 10.1007/s13593-019-0570-6

Gilles Lemaire

gilles.lemaire.inra@gmail.com

Thomas Sinclair

trsincla@ncsu.edu

Victor Sadras

Victor.Sadras@sa.gov.au

Gilles Bélanger

Gilles.belanger@canada.ca

1 Honorary Director of Research, INRA, 86600 Lusignan, France

2 North Carolina State University, Raleigh, NC, USA

3 South Australian Research and Development Institute, Waite Campus, Urrbrae, Australia

4 Agriculture and Agri-Food Canada, Québec, Canada 


\section{Box 2 Consequences for assessing $\mathbf{N}$ use efficiency by crops}

Derivative of Eq. (7) with time allows the expression of the rate of crop N uptake $\left(\mathrm{dN}_{\mathrm{upt}} / \mathrm{dt}\right)$ in relation with the crop growth rate $\left(\mathrm{dW}_{\mathrm{sh}} / \mathrm{dt}\right)$ and the shoot mass $\left(\mathrm{W}_{\mathrm{sh}}\right)$ :

$$
\mathrm{dN}_{\text {upt }} / \mathrm{dt}=\mathrm{abW}_{\text {sh }}^{\mathrm{b}-1} \times \mathrm{dW}_{\text {sh }} / \mathrm{dt} \text { Eq. }\left(7^{\prime}\right)
$$

Under non-limiting $\mathrm{N}$ supply, the crop $\mathrm{N}$ uptake rate $\left(\mathrm{dN}_{\mathrm{upt}} / \mathrm{dt}\right)$ depends on the potential crop mass accumulation rate $\left(\mathrm{dW}_{\text {sh }} / \mathrm{dt}\right)$, but it declines as crop mass increases. Devienne-Barret et al. (2000) showed that the rate of crop N uptake is dependent on both crop growth rate and soil N availability leading to a family of $\mathrm{N}_{\text {upt }}-\mathrm{W}_{\mathrm{sh}}$ trajectories for each steady state condition of soil $\mathrm{N}$ supply as represented in Fig. 4 . This dual dependency of $\mathrm{N}$ uptake is well explained by physiological evidence on feed-back regulation of root absorption capacity of mineral $\mathrm{N}$ (nitrate and ammonium) by shoot growth through C and N signals (Gastal and Saugier 1989; Lejay et al. 1999).

If $\mathrm{N}_{\mathrm{f}}$ represents the rate of $\mathrm{N}$ fertilizer application, the Nitrogen Use Efficiency ( $\mathrm{NUE}=\mathrm{dW}_{\mathrm{sh}} / \mathrm{dN}_{\mathrm{f}}$ ) for crop mass production is a function of two components: (i) the $\mathrm{N}$ Absorption Efficiency $\left(\mathrm{NAE}=\mathrm{dN}_{\text {upt }} / \mathrm{dN}_{\mathrm{f}}\right)$ and (ii) the $\mathrm{N}$ Conversion Efficiency $\left(\mathrm{NCE}=\mathrm{dW}_{\text {sh }} / \mathrm{dN}_{\text {upt }}\right.$ ), so that:

$$
\mathrm{NUE}=\mathrm{NAE} \times \mathrm{NCE}(8)
$$

$\mathrm{dN}_{\mathrm{f}}$ being the increment in $\mathrm{N}$ fertilization rate. Then the $\mathrm{N}_{\mathrm{upt}}-\mathrm{W}_{\mathrm{sh}}$ allometry has two important consequences for analyzing variations in $\mathrm{NUE}$ due to genotype-environment-management interactions as underlined by Sadras and Lemaire (2014):

(i) NAE is partly determined by crop growth rate so that genotypes having a higher crop mass should have a higher NAE than slow growing genotypes. This effect is shown on Fig. 4 where any increment in $\mathrm{W}_{\text {sh }}$ is associated with a corresponding increment of $\mathrm{N}_{\text {upt }}$ for each $\mathrm{N}$ supply. So genotypic variation in NAE has to be compared at a similar shoot mass otherwise the difference would be trivial.

(ii) The $\mathrm{N}$ dilution process implies that $\mathrm{dN}_{\text {upt }} / \mathrm{dW}_{\text {sh }}$ decreases as shoot mass increases, so that $\mathrm{NCE}\left(\mathrm{dW}_{\mathrm{sh}} / \mathrm{dN}_{\text {upt }}\right)$ increases as shoot mass increases. Consequently, the NCE of different genotypes has also to be compared at a similar shoot mass otherwise the difference observed would be obvious with a larger crop having always a higher NCE than a smaller one. 


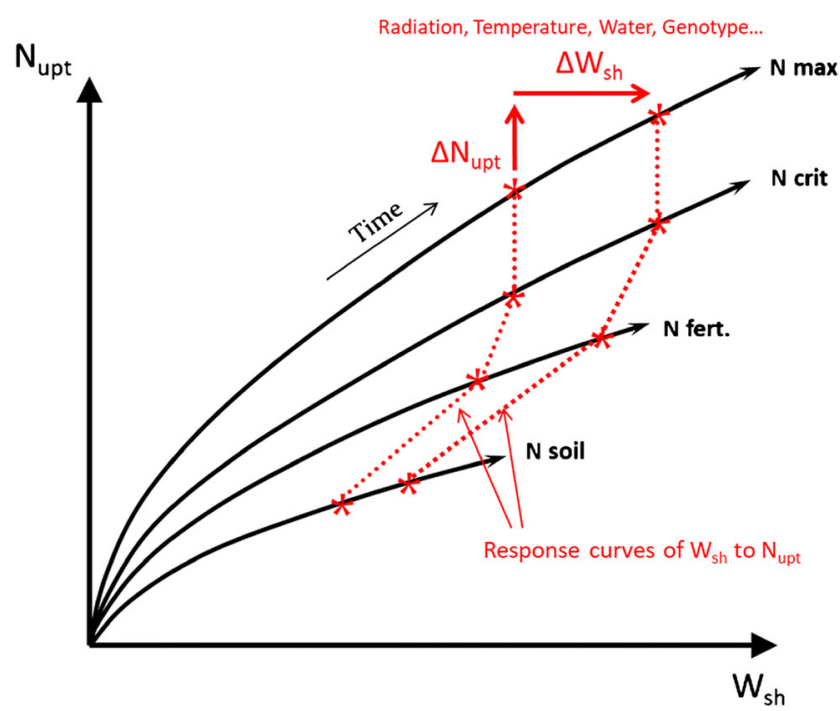

Fig. 4 Trajectories of $\mathrm{N}$ uptake as a function of shoot mass accumulation (Wsh) for different steady-state levels of $\mathrm{N}$ supply: $\mathrm{N}$ soil ( $\mathrm{N}$ supply only from the soil without any $\mathrm{N}$ fertilizer application), $\mathrm{N}$ fert ( $\mathrm{N}$ supply with a limiting $\mathrm{N}$ fertilization rate); $\mathrm{N}$ crit. ( $\mathrm{N}$ supply with a minimum $\mathrm{N}$ application for achieving maximum shoot mass accumulation); and $\mathrm{N}$ max ( $\mathrm{N}$ supply with a supra-optimum $\mathrm{N}$ fertilizer rate). Adapted from Gastal et al. (2014)
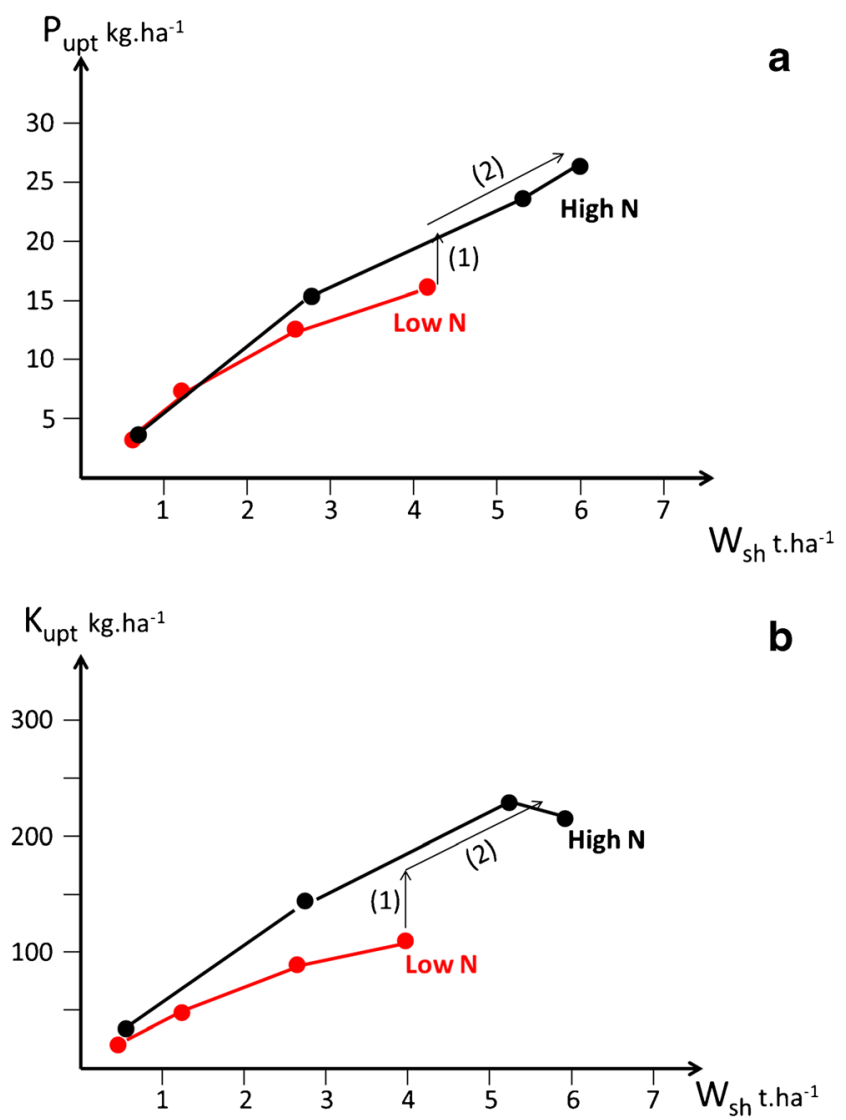

Fig. 5 Illustration of the effect of $\mathrm{N}$ supply on the allometry between $\mathrm{P}$ uptake (a) and $\mathrm{K}$ uptake (b) and shoot mass for natural grasslands. This effect can be decomposed into two parts: (1) an increase in $\mathrm{P}$ or K uptake at a similar shootmass and (2) an increase in P and $\mathrm{K}$ uptake associated to the increment in shoot mass. Adapted from Duru et al. (1992)

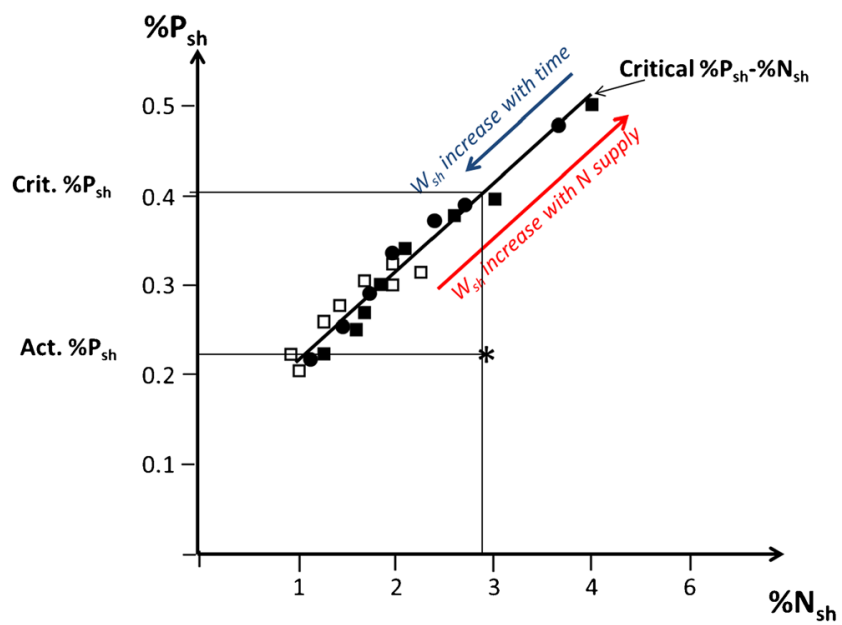

Fig. 6 Relationship between $\mathrm{P}$ and $\mathrm{N}$ concentrations in shoots (\%Psh and $\%$ Nsh expressed in per cent of dry matter) for different natural grasslands in spring under non-limiting $\mathrm{P}$ supply conditions and having received different levels of $\mathrm{N}$ supply at the end of winter: white square no $\mathrm{N}$ application; black square100 $\mathrm{kgN} \mathrm{ha}^{-1}$; black circle $150 \mathrm{kgN} \mathrm{ha}^{-1}$. The regression line $\left[\% \mathrm{Psh}=(0.091 \times \% \mathrm{Nsh})+0.133 ; \mathrm{R}^{2}=0.97\right]$ represents the "critical \%Psh." Variations in \%Nsh are due to either (i) variation in shoot mass (Wsh) due to different $\mathrm{N}$ supplies and (ii) a $\mathrm{N}$ dilution effect associated to biomass accumulation with time. A P nutrition index (PNI) can then be calculated as PNI = (Act.\%Psh)/ (Crit.\%Psh) for estimating the $\mathrm{P}$ nutrition level of a given crop. Adapted from Salette and Huché (1991) 

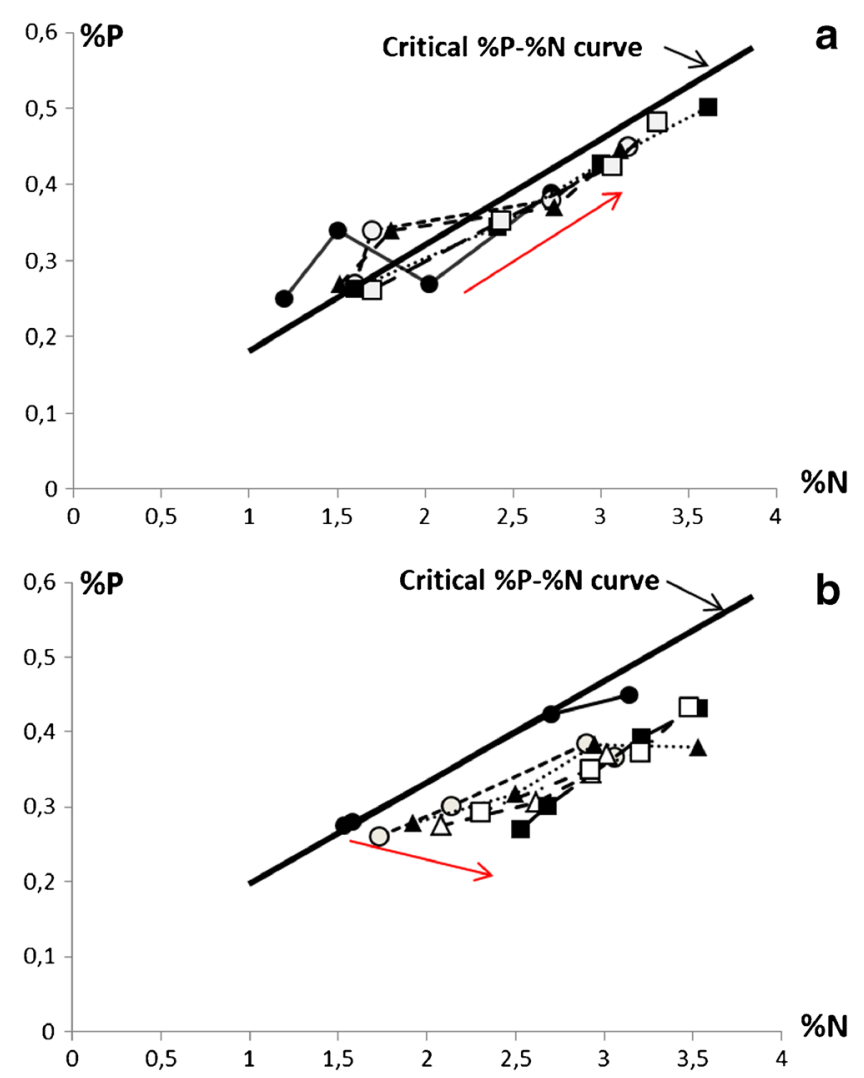

Fig. 7 Shift in the $\%$ P-\%N relationship according to the N supply of a maize crop in conditions of high (a) or low (b) soil $\mathrm{P}$ availability in eastern 0 (dark circles), 40 (open circles), 80 (dark triangles), 120 (open triangles), 160 (dark squares), and $200 \mathrm{kgN} / \mathrm{ha}$ (open squares). The critical $\% \mathrm{P}-\% \mathrm{~N}$ curve is $\% P=0.107 \% \mathrm{~N}+0.094$ as determined by Ziadi Canada. The red arrow in a indicates the positive shift in both $\% \mathrm{P}$ and $\%$ et al. (2008a, b, c). Redrawn from Ziadi et al. (2008a, b, c)

$\% \mathrm{P}$ associated with a positive shift in $\% \mathrm{~N}$

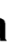

\section{b}




\section{$\% \mathrm{P}$}

Critical \%P-\%N curve
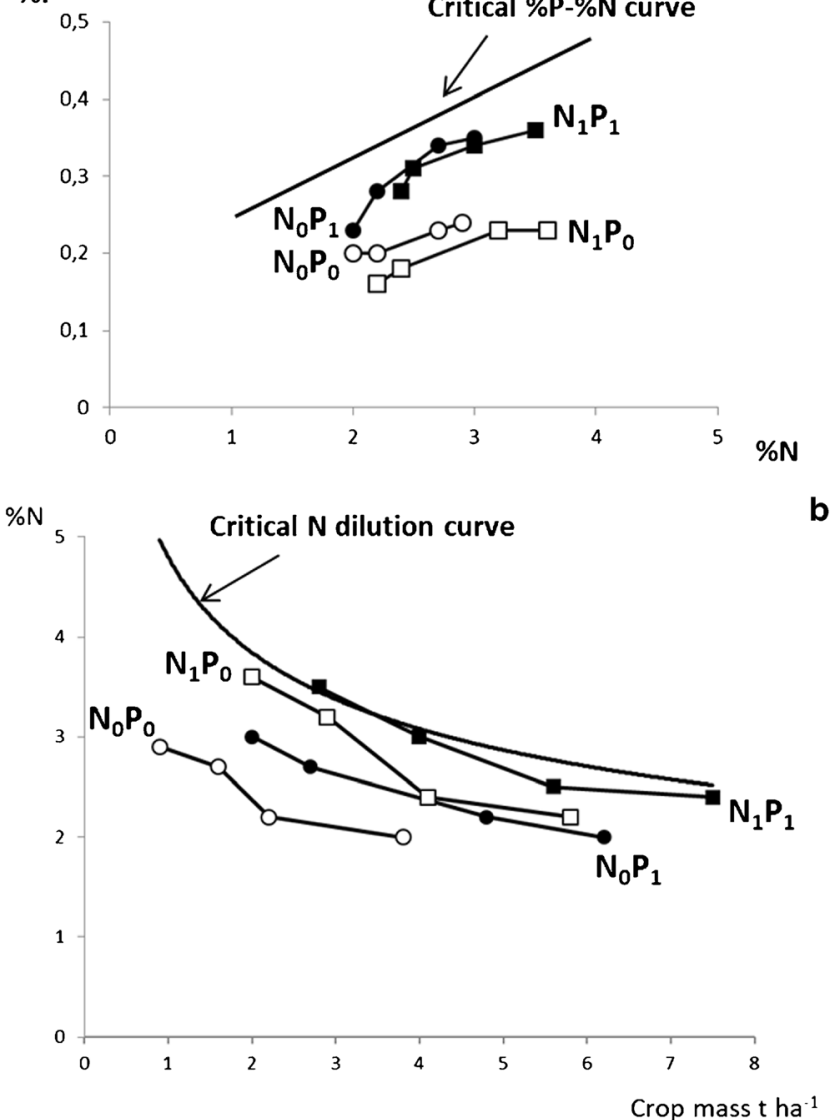

Fig. 8 Nitrogen-phosphorus interactions in natural grasslands receiving a factorial combination of high applications of $\mathrm{N}$ (squares) and $\mathrm{P}$ (dark symbols) and no application of $\mathrm{N}$ (circles) and $\mathrm{P}$ (open symbols). A Effects of the $\mathrm{N}$ and $\mathrm{P}$ supplies on shoot $\mathrm{P}$ and $\mathrm{N}$ concentration $(\mathrm{P} \%$, $\% \mathrm{~N})$; the line represents the critical $\mathrm{P}$ concentration: $\% \mathrm{Pc}=0.065 \% \mathrm{Nc}+$ 0.15 as determined by Duru and Thellier (1997). b Effects on the $\mathrm{N}$ and $\mathrm{P}$ supplies on shoot $\mathrm{N}$ concentration (N\%); the line represents the critical $\mathrm{N}$ dilution curves for C3 grasses species (Lemaire and Gastal 1997). Adapted from Duru and Ducrocq (1997)

Publisher's note Springer Nature remains neutral with regard to jurisdictional claims in published maps and institutional affiliations. 